\title{
ANIMAL-ASSISTED THERAPY SEBAGAI PENGOBATAN PASIEN AUTISM SPECTRUM DISORDER PADA ANAK
}

\author{
Jessica Sindy Sirait, Shinta Melia Desiana \\ Program Studi Sarjana Pendidikan Dokter Universitas Lampung \\ *jessicasindys@gmail.com
}

\begin{abstract}
ABSTRAK
Autism spectrum disorder (ASD) adalah developmental disability dimana seseorang mempunyai gangguan pada interaksi sosial, komunikasi, dan perilaku secara signifikan. Salah satu pengembangan yang dilakukan untuk pengobatan ASD adalah animal-assisted therapy (AAT). AAT adalah intervensi yang diarahkan pada tujuan dimana hewan yang memenuhi kriteria spesifik menjadi bagian integral dari proses pengobatan. AAT paling sering dilakukan untuk ASD adalah anjing, kuda, dan lumba-lumba. Metode yang digunakan pada penulisan ini adalah studi literature review menggunakan sumber pustaka 16 artikel/jurnal dari tahun 2011-2019. Proses pencarian sumber pustaka melalui Google Scholar, PubMed Central, dan Springer Link. Tema yang mendukung artikel ini yaituanimal-assisted therapy untuk pengobatan autism spectrum disorder. Hasil yang didapatkan menunjukkan bahwa AAT dapat mengembangkan kemampuan sosialiasi, bahasa, perilaku, serta motorik pada pasien ASD. Ulasan ini memberikan pengetahuan terkait terapi alternatif dengan hewan yang dapat dilakukan untuk pasien dengan autisme.
\end{abstract}

Kata kunci: animal-assisted therapy,gangguan spektrum autisme

\section{ANIMAL-ASSISTED THERAPY AS A TREATMENT FOR AUTISM SPECTRUM DISORDER PATIENTS IN CHILDREN}

\begin{abstract}
Autism spectrum disorder (ASD) is a developmental disability that can cause significant social, communication and behavioral disorder. One of the development carried out for ASD intervention is animal-assisted therapy (AAT). AAT is a goal-directed intervention in which ananimal that meets specific criteria is an integral part of the treatmentprocess.The method used in writingliterature review studies uses article library sources, where the search proses uses Google Scholar, PubMed Central, and Springer Link. The themes in the articles collected were related to the animal-assisted therapy for autism spectrum disorder treatment. The results that collected has shown that AAT can improve social skills, language skills, behaviour, and motor skills in ASD patient. This review provides knowledge related to alternative therapy with animal that can be done to patient with autism.
\end{abstract}

Keywords: animal-assisted therapy, autism spectrum disorder

\section{PENDAHULUAN}

Autism spectrum disorder (ASD) adalah developmental disability dimana seseorang mempunyai gangguan pada interaksi sosial, komunikasi, dan perilaku secara signifikan. Cara belajar, berpikir, dan kemampuan menyelesaikan masalah pada pasien ASD berbeda dengan sebagian besar orang serta bervariasi, ada yang berbakat hingga memerlukan perhatian khusus. Diagnosis ASD sekarang melingkupi beberapa kondisi yang dulunya merupakan diagnosa yang terpisah: autistic disorder, pervasive developmental disorder not otherwise specified (PDD-NOS), dan sindrom Asperger. Seluruh kondisi ini sekarang dikenal sebagai ASD. (CDC, 2019).

Prevalensi ASD secara global meningkat tiap tahunnya. Pada tahun 2000, Autism and Developmental Disabilities Monitoring (ADDM) yang dimiliki CDC mencatat 1 dari 160 teridentifikasi ASD. Prevalensi ini terus meningkat hingga tahun 2014 tercatat 1 dari 59 anak teridentifikasi ASD. Diestimasikan satu dari 88 anak berusia 8 tahun di Amerika 
Serikat terdiagnosis autisme setiap tahun. Diagnosis ini tidak dibatasi oleh ras, etnis, dan keadaan sosioekonomi pasien. Data yang dimiliki CDC hanya terbatas pada daerah Amerika Serikat dan Eropa. (CDC, 2019) Indonesia sendiri belum memiliki statistik tersendiri secara nasional dalam hal prevalensi penderita ASD, namun diperkirakan pada tahun 2015 terdapat kurang lebih 12.800 anak penderita autisme dan 134.000 penderita autisme di Indonesia(Oktaviana, et al., 2015).

Walaupun defisit kemampuan komunikasi adalah pusat dari kriteria diagnostik untuk ASD, anak-anak dapat didiagnosis saat dari umur 12 bulan. Penelitian menunjukkan bayibayi tersebut memperlihatkan defisit tipikal pada kontak mata, ketertarikan sosial, tersenyum, dan penggunan bahasa tubuh, serta terlihat tidak mengerti percakapan sehari-hari sesuai perkembangan norma yang berlaku di populasinya. Tidak ada penemuan secara pasti apakah ASD disebabkan faktor genetika saja atau terdapat faktor lingkungan yang mempengaruhi perkembangan gen. Tidak ditemukan juga bukti definitif bahwa ada suatu gen spesifik yang dapat menyebabkan ASD. Hal ini mengilustrasikan betapa kompleks etiologi ASD untuk saat ini walaupun telah ditetapkan suatu spektrum pada gangguan ini. Pengobatan untuk ASD masih terbatas dan belum ditemukan terapi yang paling efektif sehingga pengobatan alternatif terus dikembangkan, salah satunya animal-assisted therapy(Burke \& Iannuzzi, 2014; Siewertsenet al., 2015)

Animal-assisted therapy (AAT) adalah intervensi yang diarahkan pada tujuan dimana hewan yang memenuhi kriteria spesifik menjadi bagian integral dari proses pengobatan. AAT telah menjadi pilihan terapi untuk berbagai populasi, mulai dari sekolah, rumah sakit, fasilitas untuk pengobatan jangka panjang, serta rumah pribadi. Beberapa penelitian telah mendukung konsep bahwa terapi yang berhubungan dengan binatang akan sangat efektif untuk anak-anak yang memiliki ASD. Sebagai contoh, penelitian menunjukkan anak-anak dengan ASD cenderung lebih menyukai gambar-gambar binatang daripada gambar manusia dan tidak lebih responsif pada suara manusia daripada stimulus suara yang lain. Memperkenalkan anjing kepada anak-anak dengan ASD memberikan hasil penurunan tingkat stress, ansietas, dan iritasi serta memberikan lingkungan yang lebih relaks untuk anak-anak tersebut. Penemuanpenemuan ini menimbulkan ketertarikan para peneliti untuk menyelidiki penggunaan AAT untuk individu yang memiliki ASD. (Burke \& Iannuzzi, 2014; Siewertsenet al., 2015).

Penelitian mengenai AAT dan hewan pendamping penting dilakukan karena telah terbukti dapat memberikan keuntungan secara fisiologis, psikologis, dan perilaku. Selain itu, hewan pada konteks terapi akan terlihat sebagai sosok yang tidak menghakimi (nonjudgmental) dan oleh karena itu terlihat lebih sedikit tidak membahayakan daripada orang dewasa, sosok yang berwenang, bahkan kawan sebaya. Penderita ASD memiliki kesulitan untuk mengerti perpektif orang lain dan, melihat kesulitan dalam persepsi ini, akan lebih mudah untuk membangun relasi bersama dengan hewan (Burke \& Iannuzzi, 2014).

Saat ini sudah banyak penelitian yang telah dilakukan untuk AAT. Hewan yang paling sering digunakan untuk terapi adalah anjing dan kuda. Walaupun diperlukan penelitian lanjutan untuk menentukan hewan mana yang paling efektif untuk AAT, tidak ditemukan perbedaan yang signifikan pada terapi dengan anjing maupun kuda (Siewertsenet al., 2015). Hewan lain yang sering digunakan untuk terapi adalah lumbalumba. Keberadaan lumba-lumba dilaporkan dapat memberikan rasa aman pada anak pengidap ASD di dalam lingkungan terapi. (Parish-Plass, 2013). Literature review ini bertujuan untukmemberikan informasi tentang animal-assisted therapy yang telah dilakukan pada penderita ASD, terkhususnya pada dog-assisted therapy, equine-assisted therapy, dan dolphin-assisted therapy.

\section{METODE}

Metode yang digunakan pada penulisan ini adalah studi literature review menggunakan sumber pustaka 16 artikel/jurnal dari tahun 2011-2019 dan setelah itu penulis melakukan 
sintesa. Proses pencarian sumber pustaka melalui Google Scholar, PubMed Central, dan Springer Link. Kata kunci pencarian yang digunakan antara lain autism spectrum disorder dan animal-assisted therapy.

\section{HASIL}

Hasil penelitian dari literature review menyajikan penelitian mengenai animalassisted therapy dengan fokus pada dogassisted therapy, equine-assisted therapy, dan dolphin-assisted therapy terhadap penderita autism spectrum disorder yang telah dikumpulkan dalam pencarian artikel serta mendapatkan hasil penelitian sebagai berikut.

Penelitian Berry et al (2013) Use of Assistance and Therapy Dogs for Children with Autism Spectrum Disorders: A Critical Review of the Current Evidence menyajikan enam penelitian terapi dengan anjing keluarga yang memiliki anak pengidap ASD, terdiri atas dua penelitian menggunakan assistance dog (anjing asisten) dan empat penelitian menggunakan therapy dog (anjing terapi). Penelitian pertama memiliki jumlah sampel sebanyak 10 dan dilakukan dengan metode pengambilan data semistructural interview kepada orang tua dari setiap keluarga. Keberadaan anjing asisten tidak hanya mempengaruhi kemampuan komunikasi anak, namun juga memiliki efek yang menguntungkan pada perilaku anak dengan berkurangnya anxietas dan amarah, meningkatkan ketenangan, berkurangnya frekuensi tantrum, waktu tidur lebih terkendali, serta meningkatkan rasa aman sehingga memperbaiki kualitas dan kuantitas waktu tidur serta kemandirian anak. Penelitian kedua memiliki jumlah sampel sebanyak 42 dan dilakukan dengan desain penelitian pre-test and post-test design.

Dilaporkan bahwa beberapa perilaku problematik berkurang setelah dikenalkan dengan anjing asisten. Hal ini berhubungan dengan kadar cortisol awakening response (CAR) yang ditemukan menurun secara perlahan saat anjing hadir hingga mencapai $48 \%$ dan meningkat lagi saat anjing dilepaskan dari keluarga tersebut. Empat penelitian lain yang menggunakan anjing terapi dilaporkan terjadi perubahan signifikan pada kemampuan sosial dan komunikasi anak. Terjadi peningkatan interaksi sosial baik secara verbal maupun non verbal setelah pertemuan dengan anjing terapi, penggunaan bahasa yang lebih luas, pengurangan perilaku negatif (perilaku agresif fisik dan verbal, perilaku repetitif, self-absorption) serta peningkatan perilaku positif (bermain, kontak mata, tersenyum) pada terapis dan benda mati.

Penelitian(Borgi et al., 2015)Effectiveness of a Standardized Equine-Assisted Therapy Program for Children with Autism Spectrum Disorder dilakukan kepada 28 anak yang memiliki ASD. Terapi ini dilakukan dengan cara melakukan aktivitas terstruktur dengan kuda didampingi oleh terapis. Sampel penlitian terbagi atas kelompok yang menjalani program EAT dan kelompok kontrol. Penelitian ini menggunakan pengukuran Vineland Adaptive Behaviour Scale (VABS) dan tes Tower of London (TOL). VABS dilakukan dengan melakukan semi-structured interview kepada orang tua atau pengasuh anak dan menilai empat aspek yang terdiri atas Communications (komunikasi), Daily Life Skills (keterampilan sehari-hari), Socialization (sosialisasi), dan Motor Skills (kemampuan motorik). Tes TOL dilakukan untuk menilai kemampuan eksekusi, secara spesifik untuk mendeteksi defisit pada kemampuan perencanaan dan kemampuan menyelesaikan masalah.

Penelitian dilakukan selama 6 bulan dan dievaluasi setiap 30 hari. Hasil yang didapatkan adalah kemampuan sosialisasi dan kemampuan motorik pada kelompok EAT meningkat sementara pada kelompok kontrol tidak terjadi perubahan pada kemampuan sosialisasi dan perlahan-lahan menurun pada kemampuan motorik. Anak yang mengikuti program EAT juga mengalami peningkatan pada kemampuan menyelesaikan masalah dan peningkatan kemampuan eksekusi (waktu untuk merencanakan suatu penyelesaian masalah menjadi lebih singkat).

Penelitian Griffioen et al (2019) Verbal Interactional Synchronization between Therapist and Children with Autism 
Spectrum Disorder during Dolphin Assisted Therapy: Five Case Studies dilakukan untuk melihat sinkronisasi interaksi verbal antara terapis dan anak pengidap ASD saat menjalani dolphin-assisted therapy. Sejumlah lima anak (empat laki-laki, satu perempuan) berpatisipasi dalam penelitian ini. Mereka menjalani enam sesi terapi selama enam minggu dan pengambilan data dilakukan dengan pengambilan video saat anak menjalani terapi bersama terapis. Pada partisipan 1 dan partisipan 2 mengalami peningkatan proporsi "perilaku yang sesuai" (berbicara saat lawan bicara diam, mendengarkan saat lawan bicara sedang berbicara, dan sebagainya) setelah dilakukan perbandingan antara sesi terapi pertama dan sesi terapi terakhir, namun tidak terjadi perubahan pada partisipan 3, 4, dan 5. Tiga dari lima anak memiliki peningkatan penggunaan kata pada sesi terapi terakhir, sementara total waktu saat terapis berbicara berkurang, menunjukkan peningkatan inisiasi berbicara saat berkomunikasi dengan terapis. Hal yang paling mempengaruhi penelitian ini adalah kemampuan komunikasi dan berbahasa pada partisipan 1 dan 2 diketahui lebih baik dibandingkan partisipan 3, 4, dan 5. Hal lain yang mempengaruhi adalah lumba-lumba tidak selalu sama saat dilakukan terapi dan penelitian ini dilakukan bersama dengan tiga terapis yang berbeda.

\section{PEMBAHASAN}

Gejala yang dimiliki pada anak pengidap ASD dapat bervariasi dari ringan hingga berat dalam kaitannya dengan fungsi kognitif, gangguan sosial, serta intensitas perilaku dan preokupasi yang terbatas, repetitif, dan stereotip. Orang-orang dengan autisme akan cenderung lebih berupaya dalam situasi yang penuh tekanan atau situasi yang berubah-ubah, dan bisa jadi lebih sensitif pada stimulasi yang terjadi dalam lingkungan mereka. Keadaan ini membuat anak pengidap ASD serta keluarganya mengalami terisolasi dari dunia pendidikan serta lingkungan sosial, sehingga dibutuhkan inovasi baru untuk dapat mengintervensi masalah ini. Tradisi yang terjadi pada intervensi untuk ASD sebagian besar tentang pengembangan perilaku dan belum fokus pada motivasi, ketertarikan, ataupun status emosional anak (Weitlauf et al., 2014). Maka dari itu diperlukan inovasi dan pengembangan baru untuk terapi AAT. Salah satu inovasi yang menarik minat para peneliti dan terus dikembangkan dari abad ke-19 hingga saat ini untuk terapi kesehatan mental adalah AAT(Turner, 2011).

Hewan telah diketahui sejak lama bermanfaat dalam memperbaiki kesehatan kardiovaskular, mengurangi stress dan depresi dari banyak penelitian yang menggarisbawahi hasil positif dari petfacilitated therapy (PFT) (Zaw et al., 2017). Anjing memiliki bakat dalam hal menunjukan sikap tidak menghakimi dan perilaku positif dalam segala kondisi, walaupun kepada sosok yang mungkin tidak mereka kenal, dan juga mampu pada situasi khusus memberikan "bantuan emosional" di dalam konteks AAT (Turner, 2011). Beberapa manfaat yang didapatkan dari interaksi manusia-hewan, seperti meningkatkan empati dan perhatian sosial, dapat mengakibatkan pelepasan oksitosin, hormon yang berhubungan dengan ikatan sosial.

Proses biologis yang terjadi pada ikatan social antar manusia mirip dengan yang terjadi antara manusia dan anjing (Beetz et al., 2011). Hal ini terlihat pada penelitian (Berry et al., 2013) bahwa pengidap ASD yang menjalani dog-assisted therapy mengalami pengembangan interaksi sosial dan perbaikan perilaku. Hal ini sejalan dengan penelitian (Grigore \& Rusu, 2014)bahwa kehadiran anjing saat membacakan cerita sosial dapat membawa perkembangan sosial yang penting dengan peningkatan frekuensi inisiasi sosial dan penurunan dorongan sosial dimana anak autistik biasanya harus melakukan interaksi sosial yang sesuai. Partisipan dalam penelitian ini juga lebih tertarik untuk belajar dan berlatih keterampilan sosial saat terapi karena keberadaan anjing membantu mereka membuat interaksi sosial dapat lebih dinikmati dan menyenangkan, sehingga memperkuat keterlibatan sosial mereka.

Penelitian (Borgi et al., 2015)menjadi pengembangan EAT terbaru 
sebagaipenelitian pertama yang menyelidiki efektivitas EAT terhadap kemampuan eksekusi anak pengidap ASD dengan menyelesaikan permasalahan yang dibuat secara spesifik untuk melihat defisit pada perencanaan dan penyelesaian masalah. Hasil yang didapatkan menunjukkan pengurangan waktu yang dibutuhkan partisipan dalam perencenaan penyelesaian masalah, sehingga dapat memperlihatkan pengembangan fungsi eksekusi serta generalisasi kemampuan dalam menyelesaikan masalah dimana partisipan diminta untuk melakukan serangkaian tindakan untuk mencapai tujuan yang telah diatur. Hal ini sejalan dengan (Holm et al., 2015)dimana anak yang menjalani therapeutic horseriding (THR) mengalami peningkatan dalam melakukan instruksi di rumah dan di komintas, dengan orang tua dari anak kebanyakan menghubungankan kemajuan ini dengan disebabkan pengalaman anak mereka saat sesi mengendarai kuda. Penelitian Gabriels et al (2012) juga melaporkan pengembangan kemampuan komunikasi anak dimana terjadi peningkatan perilaku ekpresif saat berkomunikasi yang dapat dipengaruhi oleh interaksi antara anak dan kuda yang melibatkan pengalaman yang melekat dan memotivasi dalam intervensi THR.

Orang-orang yang berpatisipasi pada terapi DAT harus berada di dalam air dan berinteraksi dengan lumba-lumba. Terapi bersama lumba-lumba dapat memberikan hasil yang positif berupa efek ketenangan, peningkatan kemandirian, serta perbaikan pola tidur. DAT juga dilaporkan mampu meningkatkan kemampuan berbahasa dan memori anak pengidap ASD baik dalam jangka pendek maupun jangka panjang, sehingga terapi dengan lumba-lumba disimpulkan dapat membantu anak-anak dengan gangguan kognitif (Turner, 2011).

Penelitian Griffioen et al (2019) yang berfokus pada kemampuan verbal anak pengidap ASD melaporkan terjadinya perkembangan pada kemampuan bahasa dan komunikasi. DAT juga dilaporkan memberikan perkembangan secara signifikan pada kemampuan bahasa, kemampuan berbicara, motorik kasar, dan motorik halus terhadap anak-anak yang memiliki disabilitas jika dibandingkan dengan terapi berbicara konvensional atau program terapi fisik yang dijalankan minimal kurun waktu enam bulan. DAT dapat meningkatkan rentang perhatian, motivasi, serta kemampuan bahasa dengan lebih cepat dan biaya yang dikeluarkan lebih efektif daripada terapi konvensional lainnya serta efek dari terapi dapat dipertahankan dalam periode waktu yang panjang(Fiksdal et al., 2012).

\section{SIMPULAN DAN SARAN \\ Simpulan}

Animal-assisted therapy (AAT) adalah salah satu intervensi yang telah terbukti dapat memberikan kemajuan kepada kemampuan sosial, komunikasi, dan perilaku penderita autism spectrum disorder (ASD). Hewan yang paling sering digunakan antara lain anjing, kuda, dan lumba-lumba. Hasil terapi akan berbeda-beda tergantung beratnya gejala ASD yang dialami.

\section{Saran}

Penelitian selanjutnya mampu menggali aspek lain dalam pengobatan ASD menggunakan AAT serta dapat mencakup jumlah sampel yang lebih signifikan agar mendapatkan pengobatan yang paling efektif dan hasil yang lebih maksimal.

\section{DAFTAR PUSTAKA}

Beetz, A., Kotrschal, K., Turner, D. C., Hediger, K., Uvnäs-Moberg, K., \& Julius, H. (2011). Anthrozoös A multidisciplinary journal of the interactions of people and animals The Effect of a Real Dog, Toy Dog and Friendly Person on Insecurely Attached Children During a Stressful Task: An Exploratory Study, 24(4), 349-368.

https://doi.org/10.2752/175303711X13 159027359746

Berry, A., Borgi, M., Francia, N., Alleva, E., \& Cirulli, F. (2013). Use of assistance and therapy dogs for children with autism spectrum disorders: A critical review of the current evidence. Journal of Alternative and Complementary Medicine, 19(2), 73-80. 
https://doi.org/10.1089/acm.2011.0835

Borgi, M., Loliva, D., Cerino, S., Chiarotti, F., Venerosi, A., Bramini, M., ... Cirulli, F. (2015). Effectiveness of a Standardized Equine-Assisted Therapy Program for Children with Autism Spectrum Disorder. Journal of Autism and Developmental Disorders, 46(1), 1-9. https://doi.org/10.1007/s10803015-2530-6

Burke, S. L., \& Iannuzzi, D. (2014). AnimalAssisted Therapy for Children and Adolescents with Autism Spectrum Disorders. Animals in Social Work, 120

134.https://doi.org/10.1057/978113737 2291_8

CDC. 2019. Autism Spectrum Disorder [Internet]. Available from: https://www.cdc.gov/ncbddd/autism

Fiksdal, B. L., Houlihan, D., \& Barnes, A. C. (2012). Dolphin-Assisted Therapy: Claims versus Evidence. Autism Research and Treatment, 2012, 1-7. https://doi.org/10.1155/2012/839792

Gabriels, R. L., Agnew, J. A., Holt, K. D., Shoffner, A., Zhaoxing, P., Ruzzano, S., ... Mesibov, G. (2012). Pilot study measuring the effects of therapeutic horseback riding on school-age children and adolescents with autism spectrum disorders. Research in Autism Spectrum Disorders, 6(2), 578-588.

https://doi.org/10.1016/j.rasd.2011.09. 007

Griffioen, R., van der Steen, S., Cox, R. F. A., Verheggen, T., \& Enders-Slegers, M.-J. (2019). Verbal Interactional Synchronization between Therapist and Children with Autism Spectrum Disorder during Dolphin Assisted Therapy: Five Case Studies. Animals, 9(10), 716. https://doi.org/10.3390/ani9100716
Grigore, A. A., \& Rusu, A. S. (2014). Interaction with a therapy dog enhances the effects of social story method in autistic children. Society and Animals, 22(3), 241-261. https://doi.org/10.1163/1568530612341326

Holm, M. B., Baird, J. M., Kim, Y. J., Rajora, K. B., D’Silva, D., Podolinsky, L., ... Minshew, N. (2015). Therapeutic Horseback Riding Outcomes of Parent-Identified Goals for Children with Autism Spectrum Disorder: An ABA' Multiple Case Design Examining Dosing and Generalization to the Home and Community, 44(4), 937-947. https://doi.org/10.1007/s10803-0131949-x.Therapeutic

Oktaviana, W., Amir, Y., \& Indriati, G. (2015). Identifikasi tingkat pengetahuan ibu tentang diet casein free dan gluten free pada anak autis. JOM FKp, 5(2), 677-682. Retrieved from https://jom.unri.ac.id/index.php/JOMP SIK/article/view/21390

Parish-Plass, N. Animal-Assisted Psychotherapy: Theory, Issues, and Practice. 2013. [Internet] Available from: https://books.google.co.id/books?id=5 $\mathrm{p} 12 \mathrm{~K} 4 \mathrm{pN} 2 \mathrm{iYC} \&$ printsec $=$ frontcover $\&$ $\mathrm{dq}=$ animal+assisted+psychotherapy $\& \mathrm{~h}$ $1=i d \& s a=X \& v e d=0 a h U K E w i R 6529 \mathrm{gu}$ rlAhWGfysKHbzkDdcQ6AEIKDAA\# $\mathrm{v}=$ onepage $\& \mathrm{q}=$ animal $\% 20$ assisted $\% 20$ psychotherapy $\& \mathrm{f}=$ false

Siewertsen, C. M., French, E. D., \& Teramoto, M. (2015). Autism spectrum disorder and pet therapy. Advances in Mind-Body Medicine, 29(2), 22-25. Retrieved from http://www.advancesjournal.com/open access/Siewertsen.pdf

Turner, J. (2011). Animal Assisted Therapy and Autism Intervention: A Synthesis of the Literature. Retrieved from http://opensiuc.lib.siu.edu/gs_rp/119 
Weitlauf, A. S., McPheeters, M. L., Peters, B., Sathe, N., Travis, R., Aiello, R., ... Warren, Z. (2014). Therapies for children with autism spectrum disorder: behavioral intervensions update. Rockville: Agency for Healthcare Research and Quality. Retrieved from www.effectivehealthcare.ahrq.gov/rep orts/final.cfm

Zaw, C. C., Ahmad, N. B., \& Min, M. (2017). Potential Benefits of PetFacilitated-Therapy (PFT) In Children with Autism Spectrum Disorder (ASD). Sch. J. App. Med. Sci, 5(4B), 1319-1325.

https://doi.org/10.21276/sjams 
Jurnal Ilmu Keperawatan Jiwa Volume 2 No 3, Hal 163-170, November 2019

Persatuan Perawat Nasional Indonesia Jawa Tengah 